Abstracta Iranica Abstracta Iranica

Revue bibliographique pour le domaine irano-aryen

Volume 26 | 2005

Comptes rendus des publications de 2003

\title{
Modern Iran. Roots and Results of Revolution. New Haven, Yale University Press, 2003, 379 p.
}

\section{Azadeh Kian-Thiébaut}

\section{(2) OpenEdition}

12 Journals

\section{Édition électronique}

URL : http://journals.openedition.org/abstractairanica/2891

DOI : 10.4000/abstractairanica.2891

ISSN : 1961-960X

Éditeur :

CNRS (UMR 7528 Mondes iraniens et indiens), Éditions de l'IFRI

\section{Édition imprimée}

Date de publication : 15 mai 2005

ISSN : 0240-8910

\section{Référence électronique}

Azadeh Kian-Thiébaut, « Modern Iran. Roots and Results of Revolution. New Haven, Yale University Press, 2003, 379 p. », Abstracta Iranica [En ligne], Volume 26 | 2005, document 262, mis en ligne le 08 décembre 2005, consulté le 25 septembre 2020. URL : http://journals.openedition.org/ abstractairanica/2891 ; DOI : https://doi.org/10.4000/abstractairanica.2891

Ce document a été généré automatiquement le 25 septembre 2020.

Tous droits réservés 


\title{
Modern Iran. Roots and Results of Revolution. New Haven, Yale University Press, 2003, 379 p.
}

\author{
Azadeh Kian-Thiébaut
}

1 L'ouvrage, dont la parution est saluée par plusieurs spécialistes, est une version révisée de Roots of Revolution publié en 1981, augmentée ici de trois nouveaux chapitres sur l'Iran après la révolution. Suite à un chapitre intitulé "religion et société » qui constitue un bref aperçu de l'histoire iranienne depuis l'islamisation du pays jusqu'en 1800, l'A. analyse le processus de modernisation entamé au $19^{\mathrm{e}} \mathrm{s}$. et accéléré sous Reza chah et Mohammad Reza chah et en souligne les aspects positifs et négatifs. Après avoir présenté et analysé les mouvements populaires de l'Iran moderne, notamment la révolution constitutionnelle, le mouvement pour la nationalisation de pétrole et la révolution de 1979, l'A. conclut que la population a réagi contre l'idéologie et la pratique des hommes au pouvoir tout en cherchant l'indépendance du pays. Suite à un chapitre rédigé par Yann Richard sur les penseurs politiques chi'ites des années 1960 et 1970, ces anti-impérialistes préoccupés principalement par la domination économicoculturelle de l'Occident, Keddie présente les débats en cours parmi les clercs et intellectuels religieux. Motivés par l'expérience négative du gouvernement clérical, une grande partie d'entre eux revendique aujourd'hui la séparation entre la religion et l'État.

2 Se fondant sur les travaux des spécialistes ayant effectué des recherches en Iran, notamment en langue française, N. Keddie démontre que contrairement à certaines idées reçues, la modernisation du pays a continué après la révolution de 1979, notamment dans les domaines de l'éducation, de la santé, de l'urbanisation ou encore de la famille. Les nouveaux chapitres comprennent aussi des discussions sur la mobilisation des femmes, les questions relatives aux droits de l'homme et aux droits des minorités, les relations avec les Etats-Unis, et les luttes des Iraniens pour la démocratie. L'A. conclut que les Iraniens, très créatifs, ont au cours de leur histoire 
démontré leur capacité d'introduire des changements dans le système sans avoir recours aux puissances étrangères.

INDEX

Thèmes : 4.3. Histoire de l'Iran moderne (à partir de 1905)

\section{AUTEURS}

\section{AZADEH KIAN-THIÉBAUT}

CNRS - Paris 